\title{
La primera relación sexual: papeles, escenas y secuencias*
}

Daniel Jones**

\begin{abstract}
Resumen
El artículo analiza las expectativas y experiencias relativas a la primera relación sexual de adolescentes. Es un acontecimiento enmarcado en un proceso de aprendizaje erótico, corporal y práctico que la excede temporalmente. El análisis se basa en entrevistas individuales con 22 varones y 22 mujeres, de 15 a 19 años, de estratos socioeconómicos medios y residentes en Trelew, ciudad de 100 mil habitantes en la Patagonia argentina. Los papeles esperados para varones y mujeres en su primera relación sexual son opuestos y complementarios, apareciendo en los relatos dos escenas típicas de iniciación sexual, una gradualista y la otra espontánea.
\end{abstract}

Palabras-clave: Sexualidad, Adolescentes, Iniciación sexual.

\footnotetext{
* Recebido para publicação em março de 2009, aceito em março de 2010.

** Investigador del Consejo Nacional de Investigaciones Científicas y Técnicas (CONICET). Miembro del Grupo de Estudios sobre Sexualidades, Instituto de Investigaciones Gino Germani, Universidad de Buenos Aires. jonesdaniel@speedy.com.ar
}

cadernos pagu (35), julho-dezembro de 2010:211-239. 
La primera relación sexual

First Sexual Relation: Roles, Scenes and Sequences

\begin{abstract}
The present article analyses expectations and experiences related to the first sexual relation, considering it as an event framed within a process of erotic, corporeal and practical learning that temporally exceeds its boundaries. The article is based on individual interviews with 44 teenagers (22 male and 22 female) from 15 to 19 years of age, who are members of the middle class and live in Trelew, a city of one hundred thousand inhabitants in the Argentinean Patagonia. Expected roles for girls and boys regarding their first sexual relation are both opposed and complementary and two typical scenes of sexual initiation are revealed by our informants' stories, one gradualistic and one spontaneous.
\end{abstract}

Key Words: Sexuality, Teenagers, First Sexual Relation. 
La primera relación sexual es un acontecimiento significativo para las mujeres y los varones adolescentes, que lo esperan, viven y recuerdan con intensidad.

La "primera vez" condensa dinámicas y normas sexuales y de género que operan en la construcción social de su sexualidad.

Los significados que se le atribuyen y las maneras en que tal evento tiene lugar en una cultura determinada son una expresión del tipo de valores y creencias asignadas a la sexualidad por esa sociedad (Amuchástegui, 1996:138).

Este artículo analiza las expectativas y experiencias relativas a la primera relación sexual, tanto de quienes ya la han tenido como de quienes no, basándose en entrevistas semiestructuradas individuales realizadas a 22 varones y 22 mujeres, de 15 a 19 años de edad, de estratos socioeconómicos medios y residentes en Trelew, una ciudad de 100 mil habitantes en la Patagonia argentina, hechas en 2003 y 2005. ${ }^{1}$ Con "primera relación sexual" las mujeres y los varones heterosexuales entrevistados se refieren al que es para alguien su primer encuentro sexual en el que se produce una penetración vaginal entre un varón y una mujer. ${ }^{2}$

1 Este artículo forma parte de mi tesis doctoral "Sexualidad y adolescentes. Prácticas y significados relativos a la sexualidad de adolescentes residentes en Trelew (Chubut)", realizada con una beca del Consejo Nacional de Investigaciones Científicas y Técnicas de la Argentina (CONICET) y defendida en septiembre de 2008 en la Facultad de Ciencias Sociales de la Universidad de Buenos Aires. Elegí trabajar en una ciudad mediana alejada de las grandes urbes, pues prácticamente todos los estudios sobre sexualidad de adolescentes en América latina han sido en las áreas urbanas de mayor tamaño y/o la capital del país (Pantelides y Manzelli, 2003:74).

2 Este encuentro puede ser la primera relación sexual para uno, una o ambos participantes. Decidí no abordar las relaciones sexuales de los dos únicos varones gays entrevistados, porque difieren notablemente de las de los entrevistados 
La primera relación sexual

Esta concepción coloca al coito vaginal como la práctica que define a una relación sexual heterosexual como tal, en consonancia con lo que registra la bibliografía especializada (Laumann et al., 1994:321; Heilborn, 1999:43 y 51; Bozon y Kontula, 2003:39; Sosa, 2004:137 y 209; Barrientos y Silva, 2006:136).

Gran parte de los estudios sobre sexualidad, desde una perspectiva antropológica y demográfica (Amuchástegui, 1998:116; Fuller, 2001:211; Bozon, 1998:234; Geldstein y Schufer, 2002:6; Barrientos y Silva, 2006:152), se centra en la primera relación sexual, considerándola un momento decisivo en la vida de las personas como rito de pasaje hacia la adultez o inicio de su biografía sexual. Este artículo analiza la primera relación sexual de las mujeres y los varones adolescentes como un acontecimiento enmarcado en un proceso de aprendizaje erótico, corporal y práctico de exploración sexual relacional, que la antecede y excede temporalmente y que forma parte de la construcción social de su sexualidad.

La primera relación sexual posiblemente sea el tema más abordado por las investigaciones recientes sobre sexualidad,

tanto por la aparición de la epidemia del sida (...) [como por] la evidencia, cada vez en mayor medida, de que la iniciación sexual se da fuera del matrimonio y en la adolescencia (Manzelli y Pantelides, 2007:133).

Escogí qué dimensiones analizar a partir de la hipótesis de que la primera relación sexual ${ }^{3}$ es un acontecimiento guionado a nivel cultural, interpersonal e intrapsíquico, siguiendo la analogía dramatúrgica de la teoría de los guiones de Gagnon y Simon

heterosexuales en las dimensiones aquí analizadas. Ninguna entrevistada declara haber tenido su primera relación sexual con una mujer.

3 Para facilitar la lectura, al referirme a la primera relación sexual con coito vaginal entre un varón y una mujer también utilizo las expresiones "primera vez" (la más frecuente entre estas y estos adolescentes), "iniciación sexual" (la más recurrente en la bibliografía) y "debut sexual". 
(2005). Esto significa que existen razones socialmente aceptables para tener o no relaciones sexuales por primera vez, así como papeles esperados para cada protagonista y escenas típicas de iniciación sexual. También hay una secuencia previsible de actividades eróticas que anteceden a la primera relación sexual de una persona.

Mi objetivo es reconstruir y analizar estos elementos que conforman (en el doble sentido de moldear y ser parte de) los guiones de estos y estas adolescentes relativos a la primera relación sexual. Algunas de estas dimensiones varían en dos sentidos. Por un lado, entre varones y mujeres, porque los guiones sexuales se construyen a partir de ciertas expectativas y relaciones de género que, a su vez, ellos mismos pueden reforzar. Por otro lado, según el vínculo con la persona con que se inician sexualmente, dándose las principales diferencias entre el noviazgo y las restantes relaciones. ${ }^{4}$

\section{Papeles esperados y escenas típicas}

¿Cuáles son los papeles esperados para los varones y las mujeres en su primera relación sexual? Sus relatos ilustran prescripciones de género sobre las relaciones sexuales y, a su vez, permiten reconstruir dos escenas típicas de iniciación.

Walter no ha tenido relaciones sexuales y explicita las expectativas sobre el papel que le correspondería a un varón al manifestar su distancia frente a éstas:

Te puedo decir que hasta hace dos años atrás el sexo para mí no era algo: "Quiero probarlo, quiero probarlo". Tuve muchas, muchas novias, y muchas novias después me

\footnotetext{
${ }^{4}$ Para estas y estos adolescentes el noviazgo por lo general implica: a) un compromiso afectivo con la pareja (quererla y/o estar enamorado de ella); b) un pacto tácito o presunción de monogamia, exclusividad sexual y fidelidad mutua; y c) una expectativa de continuidad del vínculo (aunque su duración es muy variable).
} 
La primera relación sexual

dijeron: "Qué boludo que sos, las veces que lo podrías haber hecho". Y lo que pasa es que no me atraía. No era que: "Lo necesito".

(Walter, varón, 17 años, no se ha iniciado sexualmente)

Hasta hace dos años a Walter no le interesaba tener relaciones sexuales, ni lo veía como una necesidad, por eso no las tuvo a pesar de estar de novio. Tiempo después, quienes habían sido sus novias le señalaron que había desaprovechado muchas posibilidades de tener relaciones con ellas. La explicación de Walter de que no "necesitaba" tenerlas remite por oposición a la idea de que la actividad sexual de los varones responde a un impulso físico que debe ser saciado, registrada por otras investigaciones sobre jóvenes en distintos países de América latina (Heilborn, 1999; Amuchástegui, 2001; Castillo, 2003; Salem, 2004; Manzelli, 2005). De esta idea, muy presente en sus testimonios, se deriva que está en la naturaleza del varón ser sujeto de deseo sexual $y$, por ende, es natural que busque su satisfacción (Pantelides et al., 1995:113; Amuchástegui, 1998:115; Barrientos y Silva, 2006:155). En consecuencia, se espera que los varones estén siempre dispuestos y con ganas de tener relaciones:

Informante: Salió el tema de tener relaciones sexuales y qué le parecía a ella [mi novia] y qué me parecía a mí.

Entrevistador: ¿Y qué dijeron?

Informante: $\mathrm{O}$ sea, el hombre siempre está de acuerdo. $\mathrm{El}$ hombre para mí siempre está de acuerdo. La mujer, por ahí, se reserva un poco. El hombre no.

(Andrés, varón, 18 años, se inició sexualmente a los 15 años con una novia)

La disponibilidad permanente implica no perder ninguna oportunidad de tener relaciones sexuales (Manzelli, 2005:138), algo que subyace al comentario hecho a Walter por sus ex novias: "Qué boludo que sos, las veces que lo podrías haber hecho". Esta observación le recuerda qué esperaban de él en tanto varón: disponibilidad e iniciativa sexual. Ambas expectativas están 
estrechamente vinculadas, y sus ex novias aluden a la segunda al dar a entender que hubieran tenido relaciones sexuales con Walter, pero que no sucedió porque él no tomó la iniciativa, y lo descalifican con el término "boludo" por no aprovechar las posibilidades sexuales que brinda estar de novio. ${ }^{5}$ El papel esperado para Walter y para estos adolescentes varones remite a una masculinidad hegemónica ${ }^{6}$ que tiene como atributo central la heterosexualidad, prescribiendo determinado deseo y un ejercicio de la sexualidad consecuente con él (Connell, 1997; Fuller, 2001; Parrini, 2007). Estas expectativas de disponibilidad e iniciativa presumen la heterosexualidad del varón, quien debe estar siempre con ganas de avanzar sexualmente a las mujeres, operando en su institución como naturalizada y obligatoria (Butler, 2001:56).

La experiencia de Matías ilustra los papeles esperados para varones y mujeres en relación a la primera vez. A los 17 años está de novio, desde hace un año y tres meses, con una chica de 15. Aunque le propuso tener relaciones sexuales, aún no lo hicieron porque su novia no se siente preparada:

E: Recién me habías dicho el tema de las relaciones, ¿lo hablan con tu novia, surge?

I: Sí, lo hemos hablado. (...) Se dio un momento en que estábamos muy bien anímicamente, y por ahí el franeleo se daba y era demasiado. Nunca, por ejemplo, ella me retó, o viceversa. Siempre hubo respeto. Las cosas se fueron

\footnotetext{
5 Los varones entrevistados consideran que, durante la adolescencia, estar de novio aumenta notablemente las posibilidades de tener relaciones sexuales. Por un lado, porque implica una interacción sexual continua y progresiva con una pareja que favorece las charlas sobre tener relaciones sexuales, y el propio hecho de tenerlas; por otro lado, porque al ser el marco más legítimo para la iniciación de las mujeres adolescentes, el noviazgo permite que accedan a tener relaciones sexuales sin temor a exponerse al desprestigio social frente a sus pares.

6 "La masculinidad hegemónica no es un tipo de carácter fijo, el mismo siempre $y$ en todas partes. Es, más bien, la masculinidad que ocupa la posición hegemónica en un modelo dado de relaciones de género, una posición siempre disputable" (Connell, 1997:39).
} 
La primera relación sexual

dando de a poco. Yo te estoy hablando que esto se dio al año. Fue justamente porque progresivamente se fue dando la confianza, entonces llegó un momento en que el tema tenía que surgir por sí solo porque se veía que veníamos avanzando cada vez más. Era demasiado manoseo, por así decirlo. Entonces se veía, obviamente, que podía llegar a terminar en cualquier otra cosa en cualquier otro momento. Un día lo hablamos y nos pusimos, bueno, yo di la iniciativa: "Bueno, mirá, sinceramente yo me estoy sintiendo feliz con vos. Y la felicidad que tengo con vos no me la da el hecho de poder tocarte o no tocarte, sino el hecho de poder compartir la relación con vos". A todo esto hay que recordar que para mí ella era el mejor apoyo afectivo. (...) Entonces, sinceramente le dije: "Será como vos digas. Yo no quiero verte infeliz por darme felicidad a mí. O sea, si yo estoy feliz con vos no implica que vos tenés que hacer cosas contra tu voluntad para que yo sea feliz". Obviamente, a mí me gusta ser feliz yo, pero verla feliz a ella también.

$\mathrm{E}:$ ¿Y qué te dijo?

I: Me dijo que no estaba preparada. Que a los 15 años no se sentía preparada.

(Matías, varón, 17 años, no se ha iniciado sexualmente)

Este relato presenta dos cuestiones recurrentes en otros testimonios: enmarca la propuesta de tener relaciones por primera vez en una escena gradualista y plantea que al varón le corresponde tomar la iniciativa y a la mujer dar el consentimiento. Matías describe a la interacción sexual con su novia como un recorrido gradual, lento y consensuado. Esta lenta progresión se refleja en frases como "las cosas se fueron dando de a poco" y "veníamos avanzando cada vez más", y el carácter consensuado en sus referencias a la confianza mutua y el respeto recíproco. Al decir "nunca ella me retó, o viceversa. Siempre hubo respeto", "respeto" significa aceptar la voluntad del otro de seguir avanzando (o no) en este recorrido sexual, donde se producen negociaciones verbales y no verbales sobre las prácticas y ritmos. 
Quien no se sintiese respetado podría advertir (verbal o gestualmente) al otro que se detenga. Aunque Matías alude al respeto mutuo, la expectativa predominante es que en la interacción sexual el varón es quien debería respetar porque lleva la iniciativa y lo que se respeta son los tiempos y preferencias de la mujer. Las y los adolescentes mencionan este respeto sobre todo en noviazgos, lo que puede entenderse porque el compromiso afectivo y el horizonte de continuidad del vínculo favorecerían que se respete la voluntad femenina. ${ }^{7}$ Para Matías llegó un momento en que habían avanzado demasiado en este recorrido: "El franeleo se daba y era demasiado. (...) Era demasiado manoseo", en alusión a que se habían besado y acariciado de manera intensa, posiblemente tocándose los genitales mutuamente, pero sin llegar a que se produzca el coito. De este modo, su relato presenta una escena gradualista donde la progresiva y consensuada interacción sexual de la pareja torna casi inevitable hablar sobre tener relaciones: "Llegó un momento en que el tema tenía que surgir por sí solo porque se veía que veníamos avanzando cada vez más". Esta escena gradualista, cuyos protagonistas por lo general son novios, aparece en otros testimonios para explicar no sólo cómo surgió la propuesta de tener relaciones sexuales por primera vez, sino también el hecho de haberlas tenido. Quienes apelan a dicha escena destacan el punto al que habían llegado en el recorrido con su pareja. En el caso de Matías, la propuesta a su novia refleja los papeles esperados para un varón y para una mujer para tener relaciones sexuales por primera vez: él lo plantea, pero la decisión final es de ella. Si bien algunas y algunos adolescentes entrevistados tomaron la iniciativa para su primera vez de manera conjunta con su pareja, conocen las expectativas de género predominantes: "Aprendimos que el varón es siempre el que da el primer paso, desde sacar a bailar a una chica hasta

7 Castillo lo considera característico del vínculo equivalente al noviazgo en Perú: "Para los y las adolescentes la relación de 'enamorados' implica respeto, (...) para los hombres significa respeto y retraso en las relaciones coitales" (Castillo, 2003:63). 
La primera relación sexual

preguntar si quiere tener relaciones sexuales", dice Joaquín. Lucía sintetiza dichos papeles:

En general los varones asumen siempre estar en el rol de que son los que están preparados para tener relaciones sexuales y que en tal caso, si no se da, son los que van a esperar a que la chica esté lista para aceptarlo. Es lo que pasa generalmente. Como que el hombre es el que tiene más la iniciativa. (Lucía, mujer, 17 años)

En esta distribución de papeles parece estar operando tanto la representación de los varones como sujetos de deseo independientes y las mujeres como sujetos de deseo moderados (Bozon, 2004a:134; Heilborn et alii, 2006:223), como el "argumento de la incapacidad personal de la mujer para expresar su deseo sexual por tímida o recatada" (Manzelli, 2005:128) que usan algunos varones para justificar por qué deben tomar la iniciativa para tener relaciones. A la mujer le corresponde aceptar o rechazar estas propuestas, como lo ilustran las que destacan que su primera vez fue sólo cuando ellas estuvieron seguras, así como la proposición de Matías a su novia:

Le dije: "Yo no quiero verte infeliz por darme felicidad a mí. Si yo estoy feliz con vos no implica que vos tenés que hacer cosas contra tu voluntad para que yo sea feliz".

Si bien le propone a su novia tener relaciones, considerándolo una consecuencia casi inevitable de los avances eróticos conjuntos, deja abierta la posibilidad de rechazo, como finalmente sucede. Así, Matías se distancia de la "lógica de la dádiva", que concibe a la actividad sexual como un bien femenino que tiene como contrapartida una alianza (Heilborn, 1999:54), por ejemplo, el matrimonio. Entre estas y estos adolescentes la recompensa para la mujer por acceder a tener relaciones sexuales es el fortalecimiento y la profundización del noviazgo. La lógica de la dádiva subyace al pedido de un varón a una mujer de tener 
relaciones por primera vez como "prueba de amor", una dinámica que no aparece en los testimonios, pero es registrada por otras investigaciones en América latina (Salem, 2004; Barrientos y Silva, 2006). Por el contrario, las palabras de Matías se orientan a evitar que su novia y el entrevistador piensen que reclama la primera relación sexual como un presente concedido por ella al costo de su malestar. No hay presiones ni extorsiones, e incluso le aclara a su novia que "la felicidad que tengo con vos no me la da el hecho de poder tocarte, sino el hecho de poder compartir la relación con vos". Con esta frase Matías prioriza la dimensión afectiva del vínculo por sobre el contacto sexual y no condiciona su continuidad a tener relaciones. Tantas aclaraciones no son casuales. Si la actividad sexual puede ser un medio de intercambio o negociación entre géneros (Salem, 2004:56), en el caso del noviazgo entre adolescentes, tener relaciones sexuales es percibido por algunas chicas como un modo de fortalecer el vínculo sentimental con su compañero, como ilustra Lucía al decir que entre sus amigas, al tener su primera vez, "había una expectativa de alguna relación más seria a nivel emocional".

Así como el relato de Matías ayudó a reconstruir una escena gradualista y los papeles esperados para la primera relación sexual, el de Belén permite completar el papel femenino y presentar una escena espontánea de iniciación sexual:

I: Yo cuando me enamoré lo hice, nada más. No es que voy a andar [tener relaciones sexuales] con todos. (...) Era un amigo del novio de mi amiga. Me lo presentaron, tuvimos una relación, nos conocimos bastante y, bueno, se dio así un día que nos juntamos. Fuimos a comer y después fuimos a la casa de él. Estábamos ahí, todo ese clima y se dio... Se dio solo. O sea, ninguno de los dos [lo] esperábamos, pero se dio.

E: ¿Y cómo? ¿Qué te llevó a tener relaciones ese día?

I: Como que me conecté mucho con él... O sea, me sentí muy identificada con él y como que estábamos bien y se dio así solo... 
La primera relación sexual

\author{
E: ¿Dónde fue? \\ I: De vacaciones, en Buenos Aires. \\ E: ¿Y cuánto tiempo se vieron? \\ I: Un mes y medio. \\ E: ¿Y después se volvieron a ver? \\ I: No, porque yo a la semana me tuve que volver [a \\ Trelew]. Así que él se queda allá y bueno... \\ (Belén, mujer, 19 años, se inició sexualmente a los 19 años).
}

Belén cuenta que su primera relación sexual fue con un joven que conoció cuando estaba de vacaciones. Su relato se orienta a legitimar esta experiencia, destacando la selectividad en cuanto al compañero sexual y la espontaneidad del encuentro. Belén sostiene que no tendría relaciones sexuales "con todos" y que sólo las tuvo cuando se enamoró de una persona, con quien se conectó e identificó mucho, enfatizando así su selectividad. Esta selectividad en cuanto al compañero sexual aparece como una prescripción para las mujeres, tanto en los testimonios de las entrevistadas como en otras investigaciones en América latina. Un estudio sobre jóvenes de San Pablo (Brasil) apunta:

De acuerdo con las normas de género observadas en este grupo, la responsabilidad de las chicas frente a la actividad sexual es la de ser activas en lo que respecta a la elección de la persona correcta. (...) La única habilidad que precisa la chica es la de decir sí o no para este o aquel compañero (Paiva, 1999:258). ${ }^{8}$

En esta línea se puede interpretar que muchas mujeres subrayen lo especial de la persona con quien tuvieron su primera vez, como ilustra Florencia:

Yo salía con mi novio hace un año y como sentía que lo quería y estaba segura de estar [tener relaciones sexuales]

\footnotetext{
8 Todas las citas de trabajos en lengua extranjera son traducciones mías de las versiones en el idioma original consignadas en las referencias bibliográficas.
} 
con él, me pareció bien estar con él. Yo lo quería, no era una persona cualquiera.

Para estas mujeres los sentimientos son un criterio fundamental para elegir a su pareja de iniciación y todas mencionan el cariño o amor por él, mientras que entre los varones sólo lo hacen algunos de los que debutaron con novias, un desequilibrio relativo a la primera vez que registran otros trabajos (Bozon y Kontula, 2003:53; Barrientos y Silva, 2006:141). Belén recalca que estaba enamorada porque su primera relación sexual fue con alguien que no era un novio, el tipo de pareja más frecuente y legítima para que una adolescente se inicie sexualmente. Aunque no da muchos detalles sobre el compañero, de su relato se infiere que se trata de una "transa", un vínculo desvalorizado por estas mujeres para tener su primera vez por el bajo compromiso afectivo y la falta de un horizonte de continuidad que por lo general lo caracterizan. ${ }^{9} \mathrm{Su}$ aclaración de que "cuando me enamoré lo hice, nada más" supone que el amor valida las relaciones sexuales para las mujeres (Rubin, 1989:135), en consonancia con lo que señalan otros estudios sobre adolescentes y jóvenes (Amuchástegui, 2001:328; Margulis, 2003:36; Sosa, 2004:136). A su vez, Belén subraya el carácter espontáneo de su primera relación sexual: "Ninguno de los dos lo esperábamos, pero se dio. (...) Como que estábamos bien y se dio así solo". Mientras que Matías enmarca su propuesta de tener relaciones en una escena gradualista que la torna muy previsible, el relato de Belén presenta otra escena típica para la primera vez cuyo rasgo definitorio es la espontaneidad. Esta escena espontánea destaca la conexión entre los protagonistas y el clima del encuentro que hicieron que, aunque Belén y su compañero supuestamente no lo esperaban, la relación sexual se

9 El término proviene del verbo "transar", que en este contexto refiere a besarse $y$ acariciarse con una persona con distintos grados de intensidad. Para las y los adolescentes la transa es un vínculo que implica una interacción predominantemente sexual, y que no exige monogamia ni exclusividad sexual a sus participantes. 
La primera relación sexual

diese. Esta escena de iniciación sexual pone el acento en la situación que se da (el clima del encuentro o una oportunidad que surge), y no en la voluntad propia y/o de la pareja de tener relaciones sexuales (en ningún momento Belén menciona sus ganas o las de su compañero). Los protagonistas no comparten un recorrido erótico y, por el contrario, aclaran que no hubo planes ni diálogos sobre tener relaciones:

I: Fue de noche, era de noche, estábamos mirando tele, no sé qué dijo de un chico y yo la empecé a cargar [bromear] y se dio.

E: ¿Y no lo habían planificado antes?

I: No. No hubo un momento para hablar. Se dio natural.

(Nano, varón, 15 años, se inició sexualmente a los 13 años con una amiga).

El énfasis en la espontaneidad permite presentar al encuentro como "natural", en oposición a una iniciación sexual planificada. La idea de que el debut sexual no se puede planificar se encuentra extendida entre jóvenes de América latina (Pantelides y Manzelli, 2003:79), según investigaciones en Argentina, México y Brasil (Necchi et al., 2000:237; Sosa, 2004:161; Bozon y Heilborn, 2006:199). Se trata de una ideología espontaneísta para la primera relación sexual, en la que "el sexo se inscribe entre aquellas actividades que pueden ser practicadas sin que se piense en ellas y que, en función de esto, no poseen ninguna programación" (Bozon y Heilborn, 2006:199). En el caso de Belén, la espontaneidad del encuentro y la selectividad en cuanto a su compañero vía el amor parecen vincularse, ya que

determinados guiones en torno al amor romántico tienden a enfatizar la espontaneidad y la no planeación durante la primera relación sexual (Sosa, 2004:161).

Entre estas y estos adolescentes, quienes protagonizan una escena gradualista casi siempre son novios, mientras que quienes 
relatan una escena espontánea no tuvieron su primera relación sexual en un noviazgo, ni los unía con su pareja una interacción sexual con cierta continuidad. En esta escena espontánea, tener relaciones sexuales es un acontecimiento que ocurre de manera imprevista, sin planificación ni ensayos entre ambos protagonistas. Como el encuentro no se inserta en un recorrido erótico conjunto, adaptan guiones interpersonales aprendidos a partir de experiencias sexuales con otras parejas. En su actuación, posiblemente haya mayor improvisación que en la escena gradualista, ya que no conocen las preferencias y ritmos sexuales de la otra persona. El gráfico 1 sintetiza los rasgos de ambas escenas.

\section{Gráfico 1: Escenas típicas de iniciación sexual}

\section{Gradualista}

Recorrido sexual progresivo con

una pareja

$\downarrow$

Torna casi inevitable hablar sobre

tener relaciones sexuales $y / 0$

tenerlas

$\downarrow$

Iniciación sexual muy previsible,

incluso planificada

Los papeles esperados para varones y mujeres en su primera relación sexual reflejan expectativas y prescripciones de

\section{Espontánea}

No hay un recorrido sexual

conjunto

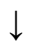

Tener relaciones sexuales es un

acontecimiento que "se da"

Iniciación sexual inesperada

(no fue hablada, ni planificada) 
La primera relación sexual

género tradicionales. ${ }^{10}$ Son papeles coherentes en sí y opuestos y complementarios entre sí, en cuanto a la iniciativa y la disponibilidad sexual que corresponden al varón y la capacidad de rechazar o consentir y la selectividad que corresponden a la mujer. Son coherentes en sí porque las dos expectativas relativas a cada papel se articulan estrechamente. La iniciativa del varón es esperable por su supuesta disponibilidad sexual permanente $\mathrm{y}, \mathrm{a}$ su vez, le permite ponerla en práctica, es decir, buscar y aprovechar las posibilidades de relaciones sexuales. En el caso de la mujer, puede ser selectiva en cuanto a su compañero de iniciación porque cuenta con la capacidad de rechazar las propuestas de relaciones sexuales o aceptarlas cuando se sienta segura. Por otra parte, estos papeles son opuestos entre sí: mientras que una mujer debería tener su primera vez con alguien "especial" y de quien estuviese enamorada, por la prescripción de selectividad, el varón tendría que aprovechar todas las oportunidades de relaciones sexuales, lo que puede implicar no ser demasiado selectivo en cuanto a su pareja de iniciación. Por último, son complementarios porque si las mujeres tienen que ser selectivas en cuanto al compañero y conservan la decisión final de tener o no relaciones sexuales es, en gran medida, porque los varones siempre estarían con ganas de tener relaciones y tomarían la iniciativa mediante avances corporales en un recorrido erótico y/o a través de una propuesta verbal. Bajo este razonamiento la mujer debería ser selectiva y ejercer su capacidad de rechazo

${ }^{10}$ Con la idea de "tradicional" designo a una concepción jerárquica y asimétrica de las relaciones de género, así como a nociones de sexualidad y normatividades para la actividad sexual rígidamente diferenciadas para varones y mujeres, que en América latina abrevan del catolicismo, el discurso patriarcal y el machismo. El "discurso patriarcal" es aquél que ha organizado los sistemas sociales y familiares en la región desde los tiempos coloniales (Cicerchia, 1998:241-242), a partir de una distinción entre actividad y pasividad que estructura las nociones de masculinidad y feminidad y que ha servido como el principio organizador de clasificación sexual (Parker, 1991:70). El "machismo" es un complejo cultural cuyos valores y símbolos justifican privilegios socialmente establecidos para los varones (Fuller, 1995; Gutmann, 2000), que exceden a la esfera sexual. 
porque no le faltarían ofertas masculinas. Esta complementariedad entre ambos papeles nos recuerda que en todo momento opera la presunción de heterosexualidad de las y los adolescentes, que no por silenciosa es menos efectiva en su institucionalización.

Cuadro 1: Papeles esperados en la primera relación sexual

\begin{tabular}{|c|c|c|}
\hline & Varón & Mujer \\
\hline $\begin{array}{l}\text { Expectativas / } \\
\text { Prescripciones }\end{array}$ & $\begin{array}{c}\text { Disponibilidad } \\
\text { permanente }\end{array}$ & $\begin{array}{c}\text { Selectividad } \\
\text { (del compañero) }\end{array}$ \\
\hline & Iniciativa & $\begin{array}{c}\text { Capacidad de rechazar } \\
\text { o aceptar (propuestas) }\end{array}$ \\
\hline
\end{tabular}

Si bien las y los adolescentes reconocen y muchas veces refuerzan estas expectativas de género, ciertas experiencias no responden a ellas. Algunas y algunos tomaron la iniciativa para tener su primera vez de manera conjunta con su pareja, una tendencia creciente en las nuevas generaciones que disuelve la separación clara entre iniciativa y consentimiento (Rodríguez, 2001:53; Bozon y Kontula, 2003:54; ORDHUM, 2005:55). No obstante, ninguna mujer dice haber tomado la iniciativa para tener su primera relación sexual y sólo un varón se la atribuye a su compañera. En lo que se refiere a la disponibilidad permanente, el hecho de que Walter no haya aprovechado sus noviazgos para iniciarse sexualmente significa que no siempre estuvo dispuesto y con ganas de tener relaciones. En cambio, no encontramos resquebrajamientos sobre la prescripción de selectividad en cuanto al compañero de iniciación: las mujeres que tuvieron relaciones sexuales siempre destacan el amor y lo especial del compañero. Frente a estas y otras respuestas que se adecuan a las expectativas de género predominantes sobre el debut sexual, como sugiere Gogna (2005:36), cabe preguntarse en qué medida reflejan lo que es culturalmente apropiado verbalizar, más que una realidad 
La primera relación sexual

inmutable y homogénea: una entrevista con una o un desconocido que se presenta como investigador universitario puede ser una buena ocasión para presentar opiniones y experiencias socialmente aprobadas.

Secuencia de actividades sexuales: la iniciación es más que un coito

Varias y varios adolescentes plantean que las charlas con su pareja sobre la primera relación sexual y el propio encuentro se enmarcaron en un recorrido progresivo de prácticas eróticas previas al coito vaginal. Analizo este recorrido con dos objetivos: reconstruir una secuencia de actividades que suelen anteceder a la primera relación coital, y destacar la dimensión gradual y procesual de la llamada "iniciación sexual", en lugar de concebirla exclusivamente como un evento. Un buen punto de partida es el relato de Meibel de su primera relación sexual con su novio:

I: Estábamos solos y al tema ya lo habíamos hablado un montón de veces y nunca había pasado nada. Y me preguntó él si no me molestaba que me empezara a tocar así. Yo le dije que no, y lo seguí yo porque él no me buscaba por el hecho de que hasta que yo no me decidiera y estuviera segura no iba a hacer nada. Y bueno, pasó... estuvimos [tuvimos relaciones sexuales]. (...)

E: ¿Y cómo fue?

I: Nos habíamos quedado solos cuidando la casa. Nos fuimos a su pieza y estuvimos viendo tele. Estábamos viendo una película, la terminamos de ver y nos empezamos a besar. Me preguntó él si no me molestaba y no, empezamos a besarnos... bueno, cuando nos quisimos acordar estábamos los dos casi desnudos, y cuando nos quisimos acordar estábamos adentro de la cama y de a poquito, tranquilo...

(Meibel, mujer, 17 años, se inició sexualmente a los 15 años con un novio). 
Precedido por otros contactos sexuales y charlas sobre tener relaciones, el recorrido erótico en este encuentro es consensuado y gradual: besarse, tocarse, desnudarse $y$, finalmente, tener la primera relación sexual, una secuencia muy semejante a la que relatan otras y otros adolescentes. Ésta comienza con besarse en la boca, abrazarse y acariciar distintas partes del cuerpo (la cara, el pelo, la espalda). Como siguiente paso el varón acaricia los pechos de la mujer y, más tarde, cada uno acaricia los genitales del otro, primero por encima de la ropa y luego por debajo. El próximo paso puede ser frotarse recíprocamente los genitales o desvestirse parcial o totalmente. Luego uno puede masturbar al otro o hacerlo mutuamente y, por último, tener relaciones coitales vaginales. En esta dinámica es habitual que el varón tome la iniciativa y la mujer acepte o no avanzar. Sobre dicho recorrido erótico quiero realizar tres observaciones.

En primer lugar, los pasos reconstruidos suponen un guión interpersonal que establece una secuencia de actividades sexuales habitual y esperable para estos varones y mujeres adolescentes. Podemos distinguir dos tipos de puesta en práctica de este guión, que simultáneamente permiten aprenderlo: a lo largo de la vida sexual de una persona y en cada encuentro sexual que participa. Respecto de la primera puesta en práctica, este guión traza un patrón ordenado de actividades sexuales que cada adolescente va conociendo y sigue en la serie de encuentros experimentados a lo largo del tiempo (con diferentes parejas o con la misma), que conforman su vida sexual. ${ }^{11}$ Quienes tienen un coito vaginal por primera vez muy probablemente antes se han besado, acariciado los genitales, masturbado mutuamente y visto parcial o totalmente desnudos en otras ocasiones, y/o lo han hecho con otras parejas. Esta serie progresiva de actividades es parte de un proceso de exploración física y relacional (Bozon y Heilborn, 2006:165) y de

${ }^{11} \mathrm{Si}$ bien me concentro en los guiones para las actividades relacionales, las autoeróticas también forman parte de su vida sexual y proveen conocimientos sexuales que pueden utilizar en la interacción con parejas. 
La primera relación sexual

aprendizaje de un saber erótico práctico y corporal (Amuchástegui, 1998), que permite coordinar y disfrutar la interacción sexual (Rodríguez, 2001:50). La reflexión de Brandão en su estudio de jóvenes de Río de Janeiro (Brasil) sintetiza cómo experimentan y aprenden este guión:

Se trata de un largo recorrido que los jóvenes atraviesan, en pareja con alguien del otro sexo, a través de caricias íntimas, el develamiento gradual del propio cuerpo y del cuerpo del otro, conversaciones, dudas y miedos, experimentación de sensaciones y sentimientos nuevos. Los avances y retrocesos, las prohibiciones a la pareja (expresadas la mayoría de las veces por las chicas) reflejan también el carácter dinámico de la aproximación, pautado por la experimentación de las dimensiones lúdica y erótica de la sexualidad y por la interiorización de las restricciones parentales y sociales (Brandão, 2004:66).

Respecto de su puesta en práctica en un encuentro, este guión establece una secuencia de actos en la cual los protagonistas habitualmente saben qué sigue (Laumann et al., 1994:110). Por la experiencia adquirida en otras ocasiones y/o con otras parejas, quien participa de una interacción sexual conoce el orden tentativo de prácticas, lo que le permite orientar sus actos $e$ interpretar los de su pareja. Esto se refleja tanto en la situación vivida por Meibel con el novio en su primera vez como en la relatada por Bebo, un varón que se inició con una transa:

Vino todo entre el manoseo. Sabés que donde te tocó, se prestó. Estábamos en el boliche, transando re calientes [excitados] y donde tocó le digo: "O vamos afuera o nada". Y dice: "Bueno, vamos".

En esta escena, Bebo sabe que el hecho de que su compañera le toque los genitales es el paso previo a tener relaciones sexuales, por eso se lo propone y ella acepta, lo que confirma su 
interpretación. La actividad sexual entre dos o más personas "depende de un descifrado continuo de códigos de conducta, de gestos y de lectura de las intenciones de los implicados para que de hecho tenga lugar" (Heilborn, 2006:38). Sin embargo, la secuencia varía entre parejas y en diferentes encuentros.

El guión que presenté es adaptado por cada pareja, tanto según las preferencias de sus miembros por determinadas actividades y su disgusto por otras, como por las negociaciones interpersonales, las opiniones de pares y las restricciones prácticas externas. La interacción sexual está mediada por preguntas, comentarios y gestos sobre lo posible, lo deseable y lo placentero (por ejemplo, acercar la mano de la otra persona para que acaricie los genitales propios o quitarla si lo está haciendo). En las diferentes adaptaciones de este guión influyen los gustos de cada actor, el grado de confianza con la pareja (entendida como comodidad mutua), el tipo de vínculo que mantienen (por ejemplo, en un noviazgo, el respeto por los tiempos de la otra persona), las redes sociales en las que se insertan (por ejemplo, las presiones de los grupos de pares para ir más rápido o más lento en el recorrido erótico) y las restricciones prácticas (como la falta de espacios para realizar ciertas actividades sexuales sin ser interrumpidos). Esto significa que varía la duración de los pasos (entre distintas parejas y en la misma pareja a lo largo del tiempo) y que no todos completan la secuencia descripta, ya que pueden saltearse prácticas (por ejemplo, se puede tener relaciones sexuales sin haberse masturbado mutuamente jamás). Hecha esta observación, de sus relatos se desprende que el orden de actividades reconstruido es muy frecuente en la interacción sexual con sus parejas.

Por último, si bien las relaciones sexuales no son la consecuencia inevitable de este recorrido erótico (como ilustra la experiencia de Matías con su novia), aparecen en sus testimonios como un horizonte habitual, posible y deseable de alcanzar mediante dicha secuencia de actividades con una pareja. Por eso enmarqué a la primera relación sexual de las y los adolescentes en 
La primera relación sexual

este recorrido para destacar la dimensión gradual y procesual de la iniciación sexual. El primer coito vaginal continúa siendo la práctica que define a la iniciación sexual como tal para sus protagonistas y para las investigaciones sociales, que en su mayoría la conciben y analizan exclusivamente como un acontecimiento. Sin embargo, la primera relación sexual de estas mujeres y varones adolescentes se inscribe en un proceso gradual de exploración sexual relacional, que la antecede y excede temporalmente, a través del cual aprenden cómo interactuar sexualmente y modelan sus deseos y placeres. Hablar con una pareja de tener relaciones sexuales por primera vez $y$, sobre todo, tenerlas, son eventos significativos para las y los adolescentes, que pierden parte de su complejidad si se analizan por fuera de este recorrido erótico.

\section{Reflexiones finales}

Este artículo partió de la hipótesis de que la primera relación sexual es un acontecimiento guionado a nivel cultural, interpersonal e intrapsíquico, del que analicé los papeles esperados para varones y mujeres, dos escenas típicas (una gradualista y otra espontánea) y una secuencia de actividades eróticas que suelen preceder a la primera relación sexual.

Los papeles esperados para varones y mujeres en su primera vez reflejan expectativas de género asimétricas y pueden favorecer interacciones coercitivas. La disponibilidad permanente y la iniciativa masculina suponen a un varón sexualmente activo, un sujeto de deseo independiente guiado por impulsos intrínsecos a su naturaleza, nociones muy extendidas en América latina (Amuchástegui, 1998; Fuller, 2001; Viveros, 2002; Salem, 2004; Heilborn et al., 2006). En cambio, a la selectividad y la capacidad de rechazar o aceptar las propuestas que definen al papel femenino subyace una concepción de la mujer como incapaz de expresar su deseo sexual, por timidez o temor al desprestigio social, y que puede controlar su deseo porque es más moderado 
que el masculino (Castillo, 2003; Bozon, 2004b; Heilborn, 2006). Bajo estas expectativas, la única actividad de la mujer sería escoger correctamente al compañero sexual entre las proposiciones recibidas. Estos papeles refuerzan relaciones sociales asimétricas y pueden conducir a interacciones sexuales coercitivas, como ilustra la situación vivida por una adolescente entrevistada: lo que Eugenia identifica como una presión de su compañero para tener relaciones sexuales, él puede considerarlo parte de su responsabilidad de llevar la iniciativa e interpretar la resistencia femenina como esperable dentro del juego de seducción. Los papeles esperados también permiten entender la presión recibida por algunos varones para iniciarse sexualmente, ya que las burlas, incitación y vigilancia de sus pares apuntan a que tengan relaciones, cumpliendo así con la prescripción de disponibilidad sexual permanente y reafirmando su masculinidad.

Sin embargo, así como los papeles esperados para la primera relación sexual reflejan prescripciones de género tradicionales, también aparecen disidencias frente a éstos. Aquellos varones que explican que se iniciaron sexualmente por la presión de sus pares cuestionan la supuesta voluntad constante de los varones de tener relaciones sexuales: su debut no está motivado por un deseo "natural", sino por un grupo de amigos que lo incita y vigila. En esta línea, que Walter no haya debutado cuando pudo hacerlo al estar de novio significa que no siempre tuvo ganas de tener relaciones, lo que pone en duda la presunta disponibilidad sexual permanente de los varones. En cuanto a la iniciativa para tener su primera relación sexual, algunas y algunos señalan que la tomaron de manera conjunta con su pareja, lo que disuelve una separación clara entre iniciativa masculina $y$ consentimiento femenino y denota cierta adhesión a un modelo más igualitario de interacción sexual.

Por último, la secuencia de actividades eróticas que suele anteceder a la primera relación sexual de estas mujeres y varones adolescentes otorga una novedosa dimensión gradual a su experiencia de iniciación. Para Lagrange y Lhomond (1997) y 
La primera relación sexual

Bozon (2004b), este carácter progresivo del pasaje a la actividad sexual coital es algo propio de las nuevas generaciones, entre las que "existe hoy un modelo de exploración física y relacional por etapas, besos profundos, caricias corporales, caricias genitales y, finalmente, penetración genital" (Bozon, 2004b:64), como el que reconstruí a partir de los testimonios. Este recorrido erótico con una o más parejas durante la adolescencia, que enmarca a su primera relación sexual, implica una ruptura respecto de las experiencias de iniciación más tradicionales en América latina: los varones con una trabajadora sexual, a modo de rito de pasaje hacia la adultez (Amuchástegui, 1998; Fuller, 2001; Viveros, 2002), y las mujeres con el marido, entregando su virginidad en la noche de bodas (Fuller, 1995; Amuchástegui, 2001; Bozon, 2006). La primera vez de estos varones y mujeres adolescentes se inscribe en un proceso gradual de exploración sexual relacional, corporal y práctico, a través del que aprenden a interactuar sexualmente y modelan sus deseos y placeres. Estas experiencias van en un sentido contrario a las expectativas de género tradicionales, $y$ suponen una modernización parcial de los guiones relativos a la primera relación sexual de las y los adolescentes. Me refiero a un proceso orientado hacia la secularización de los valores sexuales, la flexibilización de las normas de género, una mayor igualdad en las relaciones sociales $e$ interacciones sexuales, cierta individualización de los comportamientos y una creciente reflexividad del agente. Se trata de un proceso fragmentario y por momentos contradictorio pues, como sugiere esta investigación, coexisten valores y experiencias tradicionales y modernas en las y los adolescentes. Señalar que la modernización de sus guiones sexuales es parcial implica subrayar la permanencia de relaciones de género asimétricas que informan las prácticas de estos varones y mujeres. 
Daniel Jones

\section{Referencias bibliográficas}

AMUCHÁSTEGUI, Ana. Virginidad e iniciación sexual en México: experiencias y significados. México DF, EDAMEX y Population Council, 2001.

Saber o no saber sobre sexo: los dilemas de la actividad sexual femenina para jóvenes mexicanos. In: SzASZ, I. y LERNER, S. (comps.) Sexualidades en México: algunas aproximaciones desde la perspectiva de las ciencias sociales. México DF, El Colegio de México, 1998, pp.107-135.

El significado de la virginidad y la iniciación sexual: un relato de investigación. In: SZASZ, I. y LERNER, S. (comps.) Para comprender la subjetividad: investigación cualitativa en salud reproductiva y sexualidad. México DF, El Colegio de México, 1996, pp.137-172.

BARRIENTOS, Jaime y SILVA, Jimena. De la restricción hacia la equidad: las transformaciones en el comportamiento sexual en la II Región desde una mirada generacional. Antofagasta, Ediciones de la Universidad Católica del Norte, 2006.

Bozon, M. La nueva normatividad de la sexualidad en la época contemporánea. In: BARRIENTOS, J. (ed.) Construyendo una agenda temática de investigación en sexualidad. Antofagasta, Ediciones de la Universidad Católica del Norte, 2006, pp.13-27.

- A nova normatividade das condutas sexuais ou a dificuldade de dar coerência às experiências íntimas. In: HEILBORN, María Luiza. (org.) Família e sexualidade. Rio de Janeiro, FGV, 2004a, pp.119-153.

. Sociologia da sexualidade. Rio de Janeiro, FGV, $2004 b$.

. Demografia e Sexualidade. In: LoyolA, Maria Andréia. (org.) A Sexualidade nas Ciências Humanas. Rio de Janeiro, Editora UERJ, 1998, pp.227-251.

y HeILBORN, M. L. Iniciação à sexualidade: modos de socialização, interações de gênero e trajetórias individuais. In: HeIlbORN, M. L.; AQUinO, Estela; BOZON, M. y KNAUTH, Daniela. 
La primera relación sexual

(orgs.) O aprendizado da sexualidade: reprodução e trajetórias sociais de jovens brasileiros. Rio de Janeiro, Garamond, 2006, pp.155-206.

BozOn, M. y Kontula, Osmo. Sexual initiation and gender in Europe: a cross-cultural analysis of trends in the Twentieth Century. In: HUBERT, Michel; BAJOS, Nathalie y SANDFORT, Theo. (eds.) Sexual behaviour and HIV/AIDS in Europe: comparisons of national surveys. Londres, Routledge, 2003, pp.37-67.

BRANDÃO, Elaine. Iniciação sexual e afetiva: exercício de autonomia juvenil. In: HeIlbORN, M. L. (org.) Família e sexualidade. Op. cit., pp.63-86.

BUTLER, Judith. El género en disputa: el feminismo y la subversión de la identidad. México DF, Paidós, [1990] 2001.

CASTILlO, Tanya. De "todo tiene su momento" a "lo hecho, hecho está": significados de las relaciones sexuales y sus efectos en parejas adolescentes de Tahuantinsuyo Bajo, Independencia. In: CÁCERES, Carlos. (ed.) La salud sexual como derecho en el Perú de hoy. Lima, REDESS Jóvenes, 2003, pp.57-76.

CiCERCHIA, Ricardo. Historia de la vida privada en la Argentina. Buenos Aires, Troquel, 1998.

CONNELL, Robert. La organización social de la masculinidad. In: VALDÉs, Teresa y OLAVARRÍA, José. (eds.) MASCULINIDAD/ES: poder y crisis. Ediciones de las mujeres, Isis Internacional y FLACSO Chile, 1997, pp.31-48.

FULLER, Norma. Masculinidades, cambios y permanencias: varones de Cuzco, Iquitos y Lima. Lima, Fondo Editorial de la Pontificia Universidad Católica, 2001.

En torno a la polaridad marianismo-machismo. In: ARANGO, Luz; LEÓN, Magdalena y VIVEROS, Mara. (comps.) Género e identidad: ensayos sobre lo masculino y lo femenino. Bogotá, Ediciones Uniandes, 1995, pp.241-264.

GAGNON, John y SIMON, William. Sexual conduct: the social sources of human sexuality. New Brunswick, Aldine Transaction, [1973] 2005. 
Daniel Jones

GELDSTEIN, Rosa y SCHUFER, Marta. Iniciación sexual y después: prácticas de los varones jóvenes de Buenos Aires. Buenos Aires, CENEP, 2002.

GoGNA, Mónica. Estado del arte: investigación sobre sexualidad y derechos en la Argentina (1990-2002). Buenos Aires, CEDES-CLAM, 2005.

GutMann, Matthew. Ser hombre de verdad en la Ciudad de México: ni macho, ni mandilón. México DF, El Colegio de México, 2000.

HEILBORN, Maria Luiza; CABRAL, Cristiane y BOzON, M. Valores sobre sexualidade e elenco de práticas: tensões entre modernização diferencial e lógicas tradicionais. In: HEILBORN, M. L. et alii (orgs.) $O$ aprendizado da sexualidade... Op. cit., pp.207-266.

HEILBORN, M. L. Experiência da sexualidade, reprodução e trajetórias biográficas juvenis. In: HEILBORN, M. L. et alii (orgs.) $O$ aprendizado da sexualidade... Op. cit., pp.29-59.

. Construção de si, gênero e sexualidade. In: HEILBORN, M. L. (org.) Sexualidade: o olhar das ciências sociais. Rio de Janeiro, Jorge Zahar Editor, 1999, pp.40-58.

LAGRANGE, Hugue y LHOMOND, Brigitte. (dirs.) L'entrée dans la sexualité: le comportement des jeunes dans le contexte du sida. Paris, La Découverte, 1997.

LAUMANN, Edward, GagnON, J., Michael, Robert y MiCHALES, Stuart. The social organization of sexuality: sexual practices in the United States. Chicago, The University of Chicago Press, 1994.

MANZELLI, Hernán. Como un juego: la coerción sexual vista por varones adolescentes. In: PANTELIDES, Edith y LÓPEZ, Elsa. (eds.) Varones latinoamericanos: estudios sobre sexualidad y reproducción. Buenos Aires, Paidós, 2005, pp.115-144.

MANZELli, H. y PANTElides, E. La edad a la iniciación sexual y sus correlatos en varones de cuatro ciudades de América Latina. In: LÓPEZ, E. y PANTELIDES, E. (comps.) Aportes a la investigación social en salud sexual y reproductiva. Buenos Aires, CENEP-CEDES-AEPAUNFPA, 2007, pp.133-154. 
La primera relación sexual

MARGULIS, Mario. Mandatos culturales sobre la sexualidad y el amor. In: MARGULIS, M. y otros. Juventud, cultura, sexualidad: la dimensión cultural en la afectividad y la sexualidad de los jóvenes de Buenos Aires. Buenos Aires, Biblos, 2003, pp.25-43.

NECCHI, Silvia; SchuFER, Marta y MÉNDEZ RIBAS, José. Adolescentes de la Ciudad de Buenos Aires: su paso hacia la vida sexual adulta. In: PANTELIDES, E. y BOTT, Sara. (eds.) Reproducción, salud y sexualidad en América Latina. Buenos Aires, Biblos y OMS, 2000, pp.229-245.

ORDHUM - Observatorio Regional de Desarrollo Humano. Comportamiento sexual en la ciudad de Antofagasta: informe de desarrollo humano 2005. Antofagasta, 2005.

PAIVA, Vera. Cenas sexuais, roteiros de gênero e sujeito sexual. In: BARBOSA, R. y PARKER, R. (orgs.) Sexualidades pelo avesso: direitos, identidades e poder. Rio de Janeiro y San Pablo, IMS-UERJ y Editora 34, 1999, pp.249-269.

PANTELIDES, E.; GELDSTEIN, R. e INFESTA DOMÍNGUEZ, Graciela. Imágenes de género y conducta reproductiva en la adolescencia. Cuaderno del CENEP N ${ }^{\circ}$ 51. Buenos Aires, CENEP, 1995.

PANTELIDES, E. y MANZELLI, H. Investigación reciente sobre sexualidad y salud reproductiva de las/los adolescentes en América latina: qué hemos alcanzado, qué falta hacer, cuales son nuestras falencias. In: CÁCERES, C.; Cueto, Marcos; RAmOS, Miguel y VAlLENAS, Sandra. (coords.) La salud como derecho ciudadano: perspectivas $y$ propuestas desde América Latina. Lima, Universidad Peruana Cayetano Heredia, 2003, pp.73-87.

PARKER, Richard. Corpos, prazeres e paixões: a cultura sexual no Brasil contemporâneo. São Paulo, Best Seller, 1991.

PARRINI, Rodrigo. Un espejo invertido: los usos del poder en los estudios de masculinidad: entre la dominación y la hegemonía. In: AMUCHÁSTEGUI, A. y SZASZ, I. (coords.) Sucede que me canso de ser hombre: relatos y reflexiones sobre hombres y masculinidades en México. México DF, El Colegio de México, 2007, pp.95-117. 
RODRíGUEZ, Gabriela. Perdiendo los estribos: emociones y relaciones de poder en el Cortejo. Desacatos, México DF, CIESAS, PrimaveraVerano 2001, pp.35-62.

RUBIN, Gayle. Reflexionando sobre el sexo: notas para una teoría radical de la sexualidad. In: VANCE, Carole. (comp.) Placer y peligro: explorando la sexualidad femenina (selección de textos). Madrid, Hablan las mujeres, 1989, pp.113-190.

SALEM, Tania. 'Homen... já viu, né?': representações sobre sexualidade e gênero entre homens de classe popular. In: HEILBORN, M. L. (org.) Família e sexualidade. Op. cit., pp.15-61.

SoSA, Itzel. Significados de la salud y la sexualidad en jóvenes: estudio de caso en dos escuelas públicas en Cuernavaca. Tesis de Maestría en Estudios de Población y Desarrollo Regional, Universidad Nacional Autónoma de México, 2004.

VIVEROS, Mara. De quebradores y cumplidores: sobre hombres, masculinidades y relaciones de género en Colombia. Bogotá, Universidad Nacional de Colombia, 2002. 